\title{
How might we increase physical activity through dog walking?: A comprehensive review of dog walking correlates
}

\author{
Carri Westgarth $^{1 *}$, Robert M Christley ${ }^{1,2}$ and Hayley E Christian ${ }^{3}$
}

\begin{abstract}
Background: Physical inactivity and sedentary behaviour are major threats to population health. A considerable proportion of people own dogs, and there is good evidence that dog ownership is associated with higher levels of physical activity. However not all owners walk their dogs regularly. This paper comprehensively reviews the evidence for correlates of dog walking so that effective interventions may be designed to increase the physical activity of dog owners.
\end{abstract}

Methods: Published findings from 1990-2012 in both the human and veterinary literature were collated and reviewed for evidence of factors associated with objective and self-reported measures of dog walking behaviour, or reported perceptions about dog walking. Study designs included cross-sectional observational, trials and qualitative interviews.

Results: There is good evidence that the strength of the dog-owner relationship, through a sense of obligation to walk the dog, and the perceived support and motivation a dog provides for walking, is strongly associated with increased walking. The perceived exercise requirements of the dog may also be a modifiable point for intervention. In addition, access to suitable walking areas with dog supportive features that fulfil dog needs such as off-leash exercise, and that also encourage human social interaction, may be incentivising.

Conclusion: Current evidence suggests that dog walking may be most effectively encouraged through targeting the dog-owner relationship and by providing dog-supportive physical environments. More research is required to investigate the influence of individual owner and dog factors on 'intention' to walk the dog as well as the influence of human social interaction whilst walking a dog. The effects of policy and cultural practices relating to dog ownership and walking should also be investigated. Future studies must be of a higher quality methodological design, including accounting for the effects of confounding between variables, and longitudinal designs and testing of interventions in a controlled design in order to infer causality.

Keywords: Dogs, Walking, Physical activity, Review, Public health, Epidemiology, Intervention studies

\section{Background}

Increasing evidence supports the public health value of pet ownership in western countries [1,2]. The study of the relationship between dog ownership, dog walking and physical activity has recently received significant attention [3]. Many of these studies have highlighted that walking a dog could be a potentially important population-level

\footnotetext{
* Correspondence: carri.westgarth@liverpool.ac.uk

'Department of Epidemiology and Population Health, Institute of Infection and Global Health, and School of Veterinary Science, Faculty of Health and Life Sciences, University of Liverpool, Leahurst Campus, Chester High Road, Neston, Cheshire CH64 7TE, UK

Full list of author information is available at the end of the article
}

strategy for increasing physical activity, particularly as they are present in $23 \%$ of UK [4], 36\% of Australian [5] and $47 \%$ of USA households [6]. This is important because in many developed countries a large proportion of the population are not sufficiently active for health benefit [7-9]. For example, in the UK, only $39 \%$ of men and $29 \%$ of women meet the government's physical activity recommendations [9] of 150 minutes of moderate-vigorous intensity physical activity per week (usually interpreted as at least 30 minutes of physical activity on at least on five days a week) [10]. If all dog owners (between $20-40 \%$ 
of the population) briskly walked their dogs for at least 30 minutes each day they would easily achieve the recommended level of physical activity.

There is considerable evidence that dog ownership is associated with higher levels of physical activity in adults. In a meta-analysis of studies conducted to date owners who walk their dogs walked a median duration of 160 minutes per week and a median frequency of four times per week [3]. Increased physical activity has also been observed in children who have a dog [11-13] but not conclusively in adolescents $[14,15]$. A direction of causation has also been confirmed longitudinally by demonstration of an increase in walking on acquisition of a dog [16]. Further, the dog-owner relationship has the potential to enhance health to a greater degree than if walking alone or with a person. For example, walking with (vs. without) a dog has been shown to be a greater buffer against stress due to the positive effects on parasympathetic neural activity [17]. Dogs also appear to have a special ability in augmenting maintenance of physical activity over the longer term [18]. Finally, dog walking impacts both people and their pets. The exercise levels of dogs correlates well with their owners activity levels [19] and the exercise levels of dogs has been shown to be inversely associated with dog obesity, an increasing animal welfare issue [20-22].

However, a large proportion of the community who own a dog do not walk it or do so only occasionally, despite most dog owners believing that exercising their dog regularly is good for the human-animal relationship and good for the animal's health [23]. It is estimated that only $60 \%$ of dog owners walk their dog at all [3]. Owners who do not walk their dogs regularly are less likely to achieve the recommended physical activity levels compared with dog walkers [24-27], and people without a dog [28]. Furthermore, in the US there is some evidence to suggest that dog walking is decreasing in popularity as a means of physical activity [29]. Considering a significant proportion of households own dogs and many do not walk their dog regularly dog owners should be targeted in physical activity interventions. Effective strategies aimed at increasing dog owners' walking levels requires a better understanding of the correlates of dog walking [3]. Although a relatively new area of research a number of studies have examined the correlates of dog ownership, dog walking and physical activity, however to date this evidence has not been comprehensively reviewed. As dog walking is a specific behaviour different to general physical activity or even other types of walking, it requires a context specific approach to examining these correlates [30]. Using a social-ecological approach [31] we have reviewed the evidence and through this process developed a model of the physical-environment, social-environment, personal and dog-related factors associated with dog walking (Figure 1). This paper uses this model as a framework for presenting the results of our review.

\section{Aim}

Thus, the aim of this paper is to comprehensively review and summarise the evidence of the correlates of pet dog walking, to provide evidence to guide future physical activity intervention research and programs involving dog owners.

\section{Methods}

A review of all published studies from 1990-October 2012 was conducted by the primary author $(\mathrm{CW})$ and corroborated by a second author (HC), using database searches of Web of Knowledge (WoK) and Scopus. The search terms were developed to be sensitive and nonspecific, and were carried out in the format of ["Dog"" and ("exercise" or "walk" or "physical activity")] in the title, abstract, or keywords. In addition, other relevant studies were identified from prior expert knowledge and searching of bibliographies. The full search strategy is displayed in Figure 2. In order to maximise the evidence gathered we took the novel approach of including both the human health literature and the veterinary literature.

Thirty-one key studies were identified (Table 1). Due to this being a relatively new area of research, most of the studies (apart from one small pilot randomised-controlled trial) were observational cross-sectional questionnaire surveys, or qualitative interviews. Thus, the studies were not rated further for quality of methodological design as these are already considered low or very low levels of evidence by existing systematic review hierarchy of evidence grading systems [32] (e.g. level 4 of the Centre for Evidence-based Medicine grading [33]). Further methodological issues observed included small sample sizes, use of convenience samples with a high likelihood of bias, and incomplete reporting of non-significant findings. In particular, sample sizes and the use of simple univariable associations or multivariable analysis adjusting for confounding variables is noted in our results tables, as these greatly affects the strength of the evidence and should be noted when interpreting individual study findings. In addition, studies reported a number of different dog walking relevant outcomes, and considered factors measured in different ways, thus, meta-analysis was not performed.

Here we present a review of the findings from the 31 key studies identified, plus relevant supplementary information to aid in understanding and depth of evidence. Variation in quality of evidence is also reflected in our judgment of the evidence presented. Studies investigated various outcomes relevant to dog walking, for example: frequency, duration, intention to dog walk, perceptions about dog walking, regular over rare dog walking, and any dog walking over none. Most studies recruited dog 


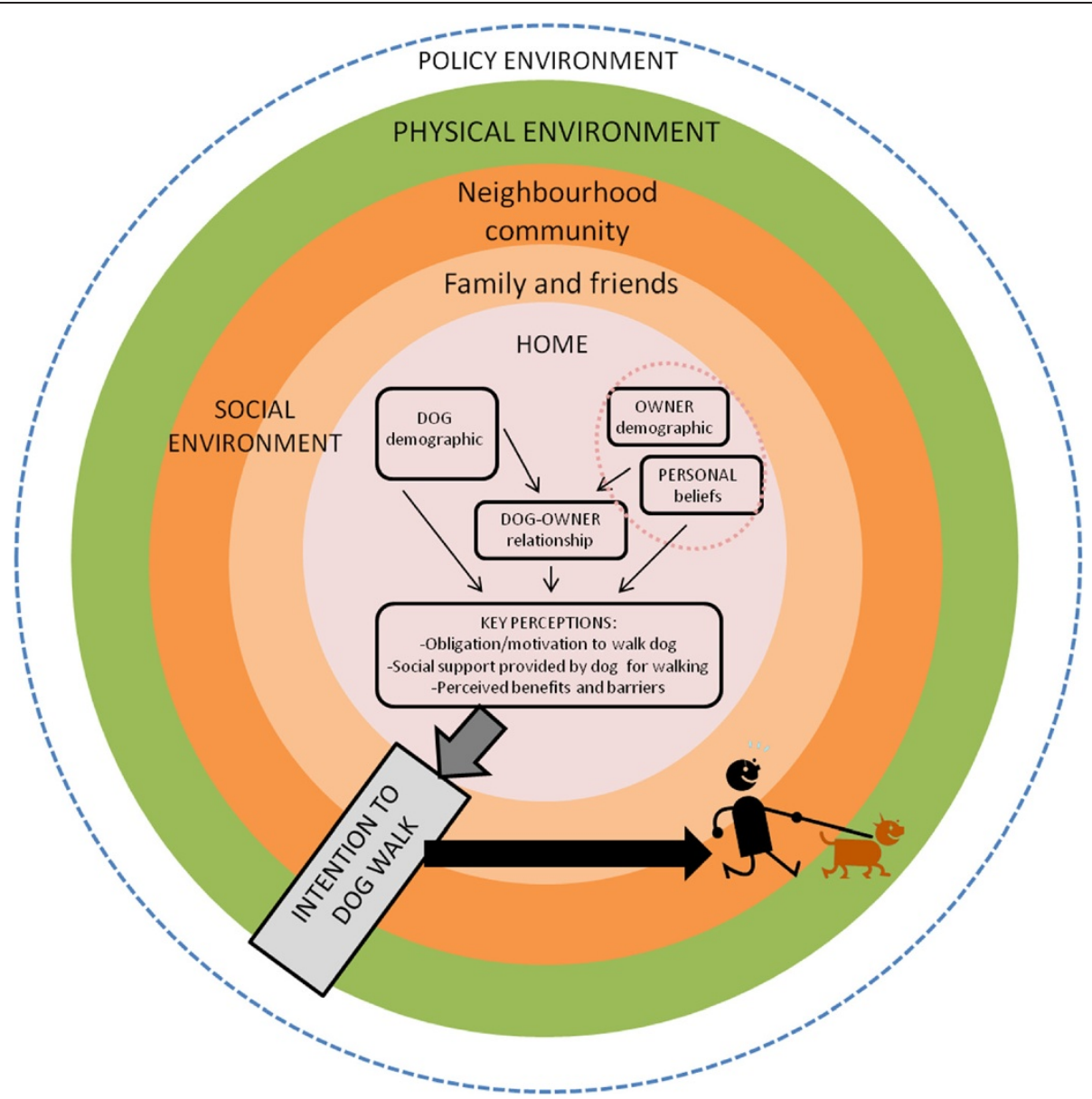

Figure 1 Social-ecological model of the correlates of dog walking.

owners and analyses were performed at the owner level, although some studies from the veterinary literature recruited dogs and were analysed at the level of the dog $(n=6)$. For these we assumed that the dog was being walked by the owner rather than an external person and thus for some studies the owner's self-report of the dog's physical activity was used for our purposes as a proxy for the owner's physical activity undertaken with their dog.

In accordance with our proposed model of dog walking behaviour, evidence of the correlates of dog walking were grouped into four categories of; dog-related (Table 2), social environment (Table 3), physical environment (Table 4), and owner-related (Table 5). Numbers presented in the tables refer to citations in the reference list.

\section{Review of the evidence of the correlates of dog walking}

Dog-related factors: Dog demographics

There was mixed evidence of an association between the number of dogs, size, type/breed, neuter status, health/ ability, or weight status and dog walking (Table 2). Although it is already known that dogs that are overweight are exercised less frequently [20-22], two key studies found no evidence of an association between dog weight status and owner's physical activity via dog walking after adjustment for other factors $[24,25]$. There was no evidence of a relationship between sex of the dog and dog walking behaviour [20,34]. Although some studies did not identify an association between dog age and walking $[26,34]$, there were a considerable number that suggested a negative association, that is younger dogs were walked more frequently and for longer periods $[16,20,35,36]$. However the complexity of age as a factor is illustrated by the suggestion that young puppies also require less walks [16].

The evidence suggests that dog walking is associated with fewer dog behaviour related problems. Owners perceive that regular dog exercise is good for dog behaviours [23] such as destruction and barking [16]. Moreover, the amount that dogs are walked is negatively associated with their fears of strangers, noises and stimuli [37], exhibiting aggression [38], lack of obedience [37], pulling on the lead 


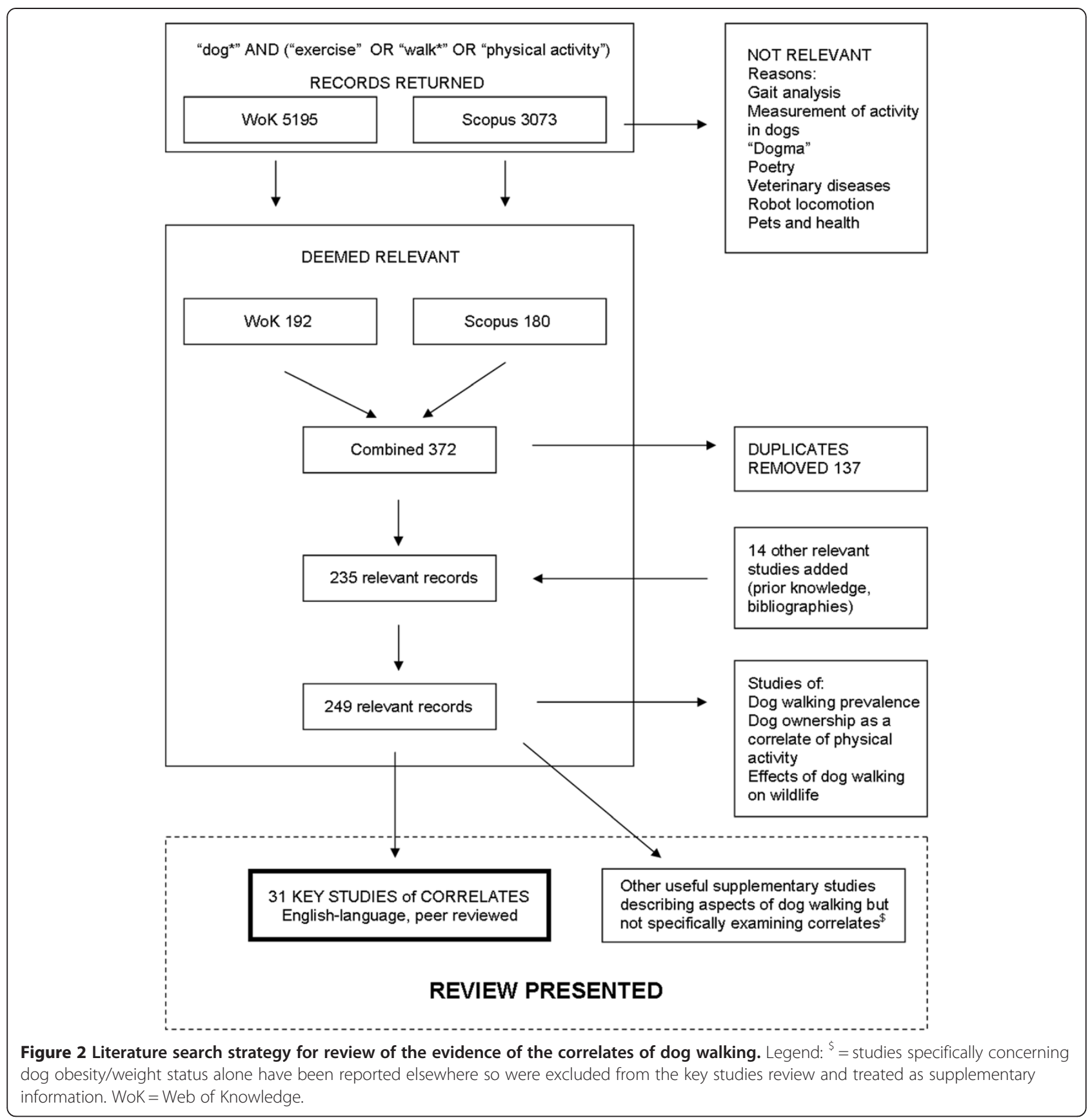

[38], and excessive barking, activity or escaping [39]. However, two studies of owner's dog walking behaviour found no association between dog behavioural problems and dog walking $[24,26]$.

Finally, there appears to be sufficient evidence of a positive association between the perceived exercise requirements of dogs and dog walking. Dogs that are thought to require considerable exercise are walked more frequently and their owners are more likely to achieve 150 minutes per week of dog walking [40]. Moreover, owners that believe that all dogs should be exercised regularly are more likely to report that their dog receives 'adequate' amounts of exercise and also report exercising them more often [23]. However, one study showed no evidence of an association between perceived exercise requirement of the dog and dog walking after adjustment for other factors [26]. Pilot intervention studies may be targeting the perceived exercise requirements of the dog (through persuasive material of the benefits of exercise on canine health) with some success, with the intervention group achieving higher step counts (1823 daily steps) than the control [41]. However, both the intervention and control 
Table 1 Summary of studies of the correlates of dog walking

\begin{tabular}{|c|c|c|c|c|c|}
\hline \multirow[t]{2}{*}{ Author } & \multirow[t]{2}{*}{ Study type } & $\mathrm{N}$ & Location & Outcomes studied & $\begin{array}{l}\text { Confounding } \\
\text { considered? }\end{array}$ \\
\hline & & \multicolumn{2}{|l|}{ Owner } & \multicolumn{2}{|l|}{ Owner PA } \\
\hline $\begin{array}{l}\text { Oka and Shibata, } \\
2012[27]\end{array}$ & Cross-sectional survey & 930 adult DO & Japan & DW yes/no & Yes \\
\hline Rohlf et al., 2012 [23] & $\begin{array}{l}\text { Cross-sectional survey } \\
\text { (non-significant variables } \\
\text { in model unknown) }\end{array}$ & 1016 adult DO & Australia & Dog exercise frequency & Yes \\
\hline Rhodes et al., 2012 [41] & $\begin{array}{l}\text { Randomised Controlled } \\
\text { Trial }\end{array}$ & $\begin{array}{l}58 \text { inactive } \\
\text { DO adults }\end{array}$ & Canada & $\begin{array}{l}\text { DW min/week and } \\
\text { pedometer step count }\end{array}$ & Yes \\
\hline Degeling et al., 2012 [40] & Cross-sectional survey & $241 \mathrm{DO}$ & Canada & $\begin{array}{l}\text { DW frequency, achieving } \\
150 \mathrm{~m} / \text { week }\end{array}$ & Yes \\
\hline $\begin{array}{l}\text { Arnberger and } \\
\text { Eder, } 2012[52]\end{array}$ & $\begin{array}{l}\text { Cross-sectional survey of } \\
\text { visitors }\end{array}$ & 330 visitors & Austria & $\begin{array}{l}\text { Perceptions of parks and } \\
\text { coping behaviours }\end{array}$ & No \\
\hline loja et al., 2011 [56] & $\begin{array}{l}\text { Park observation and } \\
\text { visitor perception survey }\end{array}$ & $\begin{array}{l}5240 \mathrm{DO} \text { and } \\
\text { NDO adults }\end{array}$ & Romania & $\begin{array}{l}\text { Frequency and length of visits plus } \\
\text { perceptions of parks }\end{array}$ & No \\
\hline $\begin{array}{l}\text { Heuberger and Wakshlag, } \\
2011 \text { [36] }\end{array}$ & Cross-sectional survey & $318 \mathrm{DO}$ adults & USA & Dogs activity, owner's exercise & No \\
\hline $\begin{array}{l}\text { McCormack et al., } \\
2011 \text { [58] }\end{array}$ & Cross-sectional survey & 506 DO adults & Canada & DW yes/no, DW frequency & Yes \\
\hline Scheibeck et al., 2011 [60] & Qualitative interview & 23 elderly DO & Austria & DW frequency and distance & No \\
\hline Hoerster et al., 2011 [26] & $\begin{array}{l}\text { Cross-sectional survey } \\
\text { (some non-significant } \\
\text { variables unknown) }\end{array}$ & 984 adult DO & USA & DW yes/no & Yes \\
\hline Christian et al., 2010 [25] & Cross-sectional survey & 483 adult DW & Australia & Regular/irregular DW & Yes \\
\hline Rohlf et al., 2010 [43] & $\begin{array}{l}\text { Cross-sectional survey } \\
\text { of exercise intentions } \\
\text { (non-significant variables } \\
\text { in model unknown) }\end{array}$ & 182 adult DO & Australia & $\begin{array}{l}\text { Dog exercise intentions, } \\
\text { dog exercise amount } \\
\text { (frequency and duration) }\end{array}$ & Yes \\
\hline $\begin{array}{l}\text { Westgarth et al., } \\
2009 \text { [34] }\end{array}$ & Cross-sectional survey & $\begin{array}{l}224 \mathrm{DO} \\
\text { households }\end{array}$ & UK & $\begin{array}{l}\text { Number of areas visited } \\
\text { on dog walks }\end{array}$ & No \\
\hline Lee et al., 2009 [57] & $\begin{array}{l}\text { 'Dog park' observation } \\
\text { and user perception survey }\end{array}$ & $\begin{array}{l}267 \text { DO who } \\
\text { use dog parks }\end{array}$ & USA & Perceptions of dog park use & No \\
\hline Coleman et al., 2008 [59] & Cross-sectional survey & $\begin{array}{l}2199 \text { adult DO } \\
\text { and NDO }\end{array}$ & USA & DW yes/no & No \\
\hline Cutt et al., 2008a [16] & Qualitative focus groups & 51 adult DO & Australia & Barriers and motivators to DW & No \\
\hline $\begin{array}{l}\text { Knight and Edwards, } \\
2008 \text { [47] }\end{array}$ & Qualitative focus groups & 65 adult DW & UK & Exploring aspects of DO and DW & No \\
\hline Cutt et al., 2008b [24] & Cross-sectional survey & 629 adult DO & Australia & DW yes/no & Yes \\
\hline Thorpe et al., 2006 [83] & Cross-sectional survey & 394 DO & USA & DW yes/no & No \\
\hline $\begin{array}{l}\text { Ham and Epping, } 2006 \\
\text { [101] }\end{array}$ & Cross-sectional survey & $\begin{array}{l}1282 \text { DW youth } \\
\text { and adults }\end{array}$ & USA & DW frequency and duration & No \\
\hline $\begin{array}{l}\text { Brown and Rhodes, } \\
2006 \text { [42] }\end{array}$ & Cross-sectional survey & $\begin{array}{l}351 \text { adult NDO } \\
\text { and DO }\end{array}$ & Canada & Walk frequency and duration & No \\
\hline $\begin{array}{l}\text { Schofield et al., } \\
2005 \text { [102] }\end{array}$ & Cross-sectional survey & $\begin{array}{l}1237 \text { adult NDO } \\
\text { and DO }\end{array}$ & Australia & Walking for leisure & No \\
\hline Suminski et al., 2005 [48] & Cross-sectional survey & $\begin{array}{l}474 \text { adult NDO } \\
\text { and DO }\end{array}$ & USA & DW yes/no & Yes \\
\hline Carver et al., 2005 [49] & $\begin{array}{l}\text { Cross-sectional survey } \\
\text { (non-significant variables } \\
\text { not presented) }\end{array}$ & 347 adolescents & Australia & DW yes/no weekends & Yes \\
\hline $\begin{array}{l}\text { Arnberger and } \\
\text { Hinterberger, } 2003 \text { [51] }\end{array}$ & $\begin{array}{l}\text { Observations of park use } \\
\text { and cross-sectional survey }\end{array}$ & $\begin{array}{l}140 \text { DW } 420 \\
\text { NDW interviewed }\end{array}$ & Austria & $\begin{array}{l}\text { Frequency and } \\
\text { duration of park visit }\end{array}$ & No \\
\hline
\end{tabular}


Table 1 Summary of studies of the correlates of dog walking (Continued)

\begin{tabular}{|c|c|c|c|c|c|}
\hline & & Dog & & Dog PA & \\
\hline $\begin{array}{l}\text { Westgarth et al., } \\
2008 \text { [35] }\end{array}$ & Cross-sectional survey & 279 dogs & UK & Walk frequency and duration & No \\
\hline Tami et al., 2008 [37] & Cross-sectional survey & $\begin{array}{l}181 \text { dogs } \\
\text { (Argentine Dogos) }\end{array}$ & Italy & Daily walk duration & No \\
\hline $\begin{array}{l}\text { Masters and McGreevy, } \\
2008 \text { [103] }\end{array}$ & $\begin{array}{l}\text { Cross-sectional survey } \\
\text { (non-significant findings } \\
\text { not presented) }\end{array}$ & 690 dogs & Australia & Walk frequency & No \\
\hline Robertson, 2003 [20] & Cross-sectional survey & 860 dogs & Australia & Land exercise yes/no & No \\
\hline Kobelt et al., 2003 [39] & Cross-sectional survey & 254 dogs & Australia & Walk frequency & No \\
\hline $\begin{array}{l}\text { Podberscek and } \\
\text { Serpell, } 1997 \text { [38] }\end{array}$ & Cross-sectional survey & $\begin{array}{l}435 \text { dogs (English } \\
\text { Cocker Spaniels) }\end{array}$ & UK & $\begin{array}{l}\text { Frequency and duration } \\
\text { of walks/exercise }\end{array}$ & No \\
\hline
\end{tabular}

PA = Physical activity, DO = Dog ownership or dog owner, NDO = Non-dog owner, DW = Dog walking or dog walker (owner who walks their dog), NDW = Non-dog walker (owner who does not walk their dog).

group were observed to increase their physical activity in this study.

\section{Dog-related factors: The dog-owner relationship}

The dog-owner relationship appears to be the most important correlate of dog walking behaviour (Table 2). The dog-owner relationship includes factors such as attachment, frequency of interactions, feelings of support and motivation provided by the dog for walking and feelings of obligation towards walking the dog. For example, Japanese dog walkers had higher levels of attachment to their dogs than owners who did not walk their dog (OR $=2.32$ 'high' compared to 'low' attachment) [27] and in a sample of Australian owners and dogs, higher scores on a dog-owner interaction scale was associated with more frequent exercise [23]. Moreover, dog owners who perceive that their dog provides motivation, companionship and/or support for walking $[16,24,25]$, or similarly, feel that the dog provides encouragement to walk [26], are more likely to walk the dog, or walk regularly with the dog. For example, not walking the dog was been shown to be significantly more likely in owners who do not perceive that their dog provides motivation $(\mathrm{OR}=9.60)$ or social support $(\mathrm{OR}=10.84)$ to walk, independent of other wellknown correlates of physical activity. Notably, 'knowing that the dog enjoys going for a walk' does not appear to be associated with dog walking when support/motivation provided by the dog is already accounted for [24,25].

'Dog obligation' is an owner's sense of obligation and/ or responsibility to walk their dog regularly and a feeling that their dog pressures them to take it for a walk [42] and has been shown to mediate the relationship between dog ownership and physical activity [26,42]. It might also encompass valuing exercise for the dog [43] and 'feelings of guilt' [16], and is likely to be related to the strength of the dog-owner relationship/attachment. As mentioned previously, pilot intervention studies suggest that targeting the canine need for exercise, rather than the human need, through 'persuasive material regarding canine health benefits', may be a helpful approach for increasing owner activity [41]. Other research outside the key studies of dog walking correlates also confirms the central motivational role for walking as an obligation to support the needs of the dog; a commonly stated reason for adherence to a loaned dog walking programme for the elderly was that the dogs "need us to walk them" [44] and owners have been observed to talk to and make reference to their dogs wishes or needs whilst walking [45]. Moreover, a study of an owner-pet combined weight loss program described dogs as having three distinct (from human support) positive influences of being a consistent initiator of exercise (seeking out the owner for exercise), providing enjoyment of exercise (loving walking the dog), and engendering parental pride (doing something good for the dog) [46].

\section{Social environment factors}

There was mixed evidence surrounding the motivating aspects of social facilitation that occurs during dog walking (Table 3). Although seeing other people walking their dogs has been suggested as a motivator [16,47], when investigated quantitatively, there was no evidence of an association between the perception that dog walking promotes social engagement and dog walking [26]. Three studies support the positive influence of the subjective norm of significant others in relation to dog walking $[23,24,42]$ with one study showing no association [25].

General safety concerns may be negatively associated with dog walking in females but not males [47-49]. However, two studies have shown that walking with a dog compared to without can also increase feelings of safety in the neighbourhood $[16,47]$ and other studies have found no association between safety and dog walking $[24,26]$.

Finally, social environment factors associated with the dog walking experience have been investigated. Concerns about dogs coming into contact with children or other park users and the potential for problems has been identified 
Table 2 Evidence of the DOG-RELATED (demographic and dog-owner relationship) correlates of dog walking

\begin{tabular}{|c|c|c|c|c|c|}
\hline & & $\begin{array}{c}\text { Evidence of a } \\
\text { positive association }\end{array}$ & $\begin{array}{c}\text { Evidence of a } \\
\text { negative association }\end{array}$ & $\begin{array}{l}\text { No evidence of } \\
\text { an association }\end{array}$ & $\begin{array}{l}\text { Where some elements show } \\
\text { evidence of a positive association but } \\
\text { others no evidence of an association }\end{array}$ \\
\hline \multirow{10}{*}{$\begin{array}{l}\text { Dog } \\
\text { demographic }\end{array}$} & Number of dogs & 34 & $16^{*}, 103$ & $40,26,25,24$ & \\
\hline & Dog size & 35,102 & & $\begin{array}{c}\mathbf{2 7}, 34, \mathbf{2 4}, 42 \\
39\end{array}$ & \\
\hline & Dog type/breed & 34 & & 20 & \\
\hline & Dogs age & & $36,35,20$ & 26,34 & $16^{*}$ \\
\hline & Dog sex & & & 34,20 & \\
\hline & Dog neutered & 103 & & 34,20 & \\
\hline & Dogs health/ability & $16^{*}$ & & 26,24 & \\
\hline & Dog weight status** & & 20 & 25,24 & \\
\hline & Dog behaviour problems & & $37,38,39$ & 24,26 & \\
\hline & $\begin{array}{l}\text { Perceived exercise } \\
\text { requirements }\end{array}$ & $16^{*}, \mathbf{2 3}, \mathbf{4 0}, 41$ & & 26 & \\
\hline \multirow{8}{*}{$\begin{array}{l}\text { Dog-owner } \\
\text { relationship }\end{array}$} & Dog attachment/interaction & 23,27 & & 24 & \\
\hline & $\begin{array}{l}\text { Dog encourages/supports } \\
\text { walking +companionship }\end{array}$ & $16^{*}, 24,25,26$ & & & \\
\hline & Dog obligation & $16^{*}, \mathbf{2 6}, 42$ & & & \\
\hline & Feelings of guilt & $16^{*}$ & & & \\
\hline & $\begin{array}{l}\text { Perceived benefits } \\
\text { dog health }\end{array}$ & $16^{*}, 41$ & & $24,25,26$ & \\
\hline & $\begin{array}{l}\text { Perceived benefits } \\
\text { dog behaviour }\end{array}$ & $16^{*}$ & & 24,25 & \\
\hline & $\begin{array}{l}\text { Valuation of exercise } \\
\text { for dog }\end{array}$ & $41, \mathbf{4 3}$ & & & \\
\hline & $\begin{array}{l}\text { Knowing dog enjoys } \\
\text { going for a walk }\end{array}$ & & & 24,25 & \\
\hline
\end{tabular}

*qualitative evidence. For quantitative observational studies, bolded citation number = multivariable adjusted evidence or unbolded citation number $=$ univariable evidence. **Studies specifically concerning dog obesity/weight status alone have been reported elsewhere so were excluded from the key studies review and treated as supplementary information.

as a barrier to dog walking [16]. Moreover, crowded environments can discourage some dog walkers as they feel it interferes with walking their dog unleashed [50-52]; and they may put their dog on a leash or go home earlier than planned [52]. The evidence also suggests that factors related to other people's dogs are negatively associated with dog walking. Two studies show that fear of coming into contact with other dogs is a barrier, in particular fear of large dogs, small feisty dogs, certain breeds, off-leash, uncontrolled, untrained

Table 3 Evidence of the SOCIAL ENVIRONMENT correlates of dog walking

\begin{tabular}{|c|c|c|c|}
\hline & $\begin{array}{c}\text { Evidence of a } \\
\text { positive association }\end{array}$ & $\begin{array}{c}\text { Evidence of a } \\
\text { negative association }\end{array}$ & $\begin{array}{l}\text { No evidence of } \\
\text { an association }\end{array}$ \\
\hline Perception that DW promotes social engagement & $16^{*}, 47^{*}$ & & 26 \\
\hline Subjective norm of significant others about dog walking & $23,24,42$ & & 25 \\
\hline $\begin{array}{l}\text { Other people's dogs (e.g. large, uncontrolled, } \\
\text { roaming, untrained, off leash, aggressive, fear) }\end{array}$ & & $16^{*}, 49$ & \\
\hline Other dog owners not picking up after dog & & $16^{*}$ & \\
\hline Safety concerns & & $47^{*}, 48,49$ & 24,26 \\
\hline $\begin{array}{l}\text { DW perceived as a deterrent for local } \\
\text { crime/increasing feelings of safety }\end{array}$ & $16^{*}, 47^{*}$ & & \\
\hline Conflict with other users of DW areas & & $16^{*}$ & \\
\hline Crowding in DW areas & & $51,52^{*}$ & \\
\hline
\end{tabular}

DW=Dog walking. *qualitative evidence. For quantitative observational studies, bolded citation number $=$ multivariable adjusted evidence or unbolded citation number $=$ univariable evidence. 
Table 4 Evidence of the PHYSICAL ENVIRONMENT correlates of dog walking

\begin{tabular}{|c|c|c|c|}
\hline & $\begin{array}{c}\text { Evidence of a } \\
\text { positive association }\end{array}$ & $\begin{array}{c}\text { Evidence of a } \\
\text { negative association }\end{array}$ & $\begin{array}{l}\text { No evidence o } \\
\text { an association }\end{array}$ \\
\hline $\begin{array}{l}\text { Accessibility/proximity to walking areas } \\
\text { (particularly off-leash) }\end{array}$ & $56^{*}, \mathbf{2 5}, \mathbf{4 3}, 57,16^{*}, \mathbf{4 9}, 51$ & 58 & 24,48 \\
\hline Indicate take dog to 'dog park' specific area & & & 26 \\
\hline Park aesthetics/footpath provision/size/lighting/fencing & $16^{*}, 56^{*}$ & & \\
\hline Dog-supportive features/enrichments and separate children's play area & $16^{*}, 25,56^{*}$ & & 24,58 \\
\hline Neighbourhood street pattern & & & 48 \\
\hline Neighbourhood aesthetics & & & 26,48 \\
\hline Neighbourhood walkability & 59 & & \\
\hline Urbanicity & & & 101 \\
\hline Type of residence (attached vs separate) & $40,58,60^{*}$ & & 27 \\
\hline Backyard size & & $16^{*}$ & 39 \\
\hline Weather/temperature & & $57^{*}$ & 51 \\
\hline
\end{tabular}

*qualitative evidence. For quantitative observational studies, bolded citation number $=$ multivariable adjusted evidence or unbolded citation number $=$ univariable evidence.

or roaming dogs, and owners not adequately picking up after their dogs $[16,49]$.

\section{Physical environment factors}

Access to, and quality of, dog-supportive features of parks were positively associated with dog walking (Table 4). Both key and supplementary studies show that being able to walk their dog off-leash is important for many dog owners [16,53-55]. Accessible public open space for dogs and the provision of dog-related infrastructure within walking areas are also important to dog owners (e.g. clear signage, dog litter bags and bins, accessible water sources, fencing around designated off-leash areas, separation from children's play areas, dog agility equipment, parks not being located near to busy roads and being well-fenced) $[16,56]$. For example, owners who have access to a dogsupportive park within their neighbourhood are more likely to walk their dog regularly compared to rarely [25]. Furthermore, lack of access to appropriate walk areas is associated with reduced 'intention' to walk the dog [43].

Table 5 Evidence of the OWNER RELATED (Demographic and personal beliefs) correlates of dog walking

\begin{tabular}{|c|c|c|c|c|c|}
\hline & & $\begin{array}{c}\text { Evidence of a } \\
\text { positive association }\end{array}$ & $\begin{array}{c}\text { Evidence of a } \\
\text { negative association }\end{array}$ & $\begin{array}{l}\text { No evidence of } \\
\text { an association }\end{array}$ & $\begin{array}{l}\text { Where some elements } \\
\text { show evidence of a positive } \\
\text { association but others no } \\
\text { evidence of an association }\end{array}$ \\
\hline \multirow[t]{11}{*}{ Demographics } & Gender (female) & 40,58 & & $\mathbf{2 7}, \mathbf{2 6}, 59,83,101, \mathbf{4 8}$ & \\
\hline & $\begin{array}{l}\text { Age (middle aged } \\
\text { sometimes most likely) }\end{array}$ & $\mathbf{2 3}, \mathbf{5 8}, 101$ & & $\mathbf{2 7}, \mathbf{4 0}, 34,59, \mathbf{4 8}$ & \\
\hline & Ethnicity (white) & 59,83 & & & \\
\hline & Education & $\mathbf{5 8}, 83$ & & $27,40,59,48$ & \\
\hline & Employment & & & 27,34 & \\
\hline & Income & $27, \mathbf{4 0}, \mathbf{2 6}, 101$ & & 59 & \\
\hline & Health & & & $\mathbf{5 8}, 83$ & \\
\hline & Weight status & & $\mathbf{5 8}, 59,83$ & & \\
\hline & $\begin{array}{l}\text { Other people in household or } \\
\text { dependents living at home }\end{array}$ & 58 & & $\mathbf{2 7}, 34,83$ & \\
\hline & Marital status & 27 & & & \\
\hline & Others in household walk dog & & & $24,25,26$ & \\
\hline \multirow[t]{2}{*}{ Personal beliefs } & $\begin{array}{l}\text { Theory of Planned } \\
\text { Behaviour constructs }\end{array}$ & 26,43 & & & 42 \\
\hline & Lack of time & & $43,57^{*}$ & & \\
\hline
\end{tabular}

For quantitative observational studies, bolded citation number = multivariable adjusted evidence or unbolded citation number = univariable evidence. 
However, owners who take their dog to a specifically designated 'dog park' (see [57]) are no more or less likely to dog walk than those who do not [26]. There is also evidence that owners who live within $1.6 \mathrm{~km}$ of a park with off-leash areas may be least likely to participate in dog walking at all $[24,58]$ but if they do walk with their dog the frequency [58] and the minutes spent [25] dog walking is higher.

There is also evidence that many of the physical environmental barriers and facilitators to general walking appear to also affect dog owners (e.g. park attractiveness, good lighting, footpath connectivity, wide footpaths on both sides of the road) $[16,56]$. For example, dog walkers are more likely to live in high walkable neighbourhoods [59] and parents of children who walk dogs report better access to areas for exercise in their neighbourhoods than do parent of children who do not walk dogs [49]. However, other studies show no evidence of an association between neighbourhood aesthetics or street pattern [26,48] and dog walking behaviour. Whilst only one study has investigated the association between urbanisation and dog walking there is sufficient evidence of a positive association between living in attached housing compared with detached and dog walking frequency $[40,58]$ although this association was not supported in a Japanese study [27]. The positive association between living in attached housing and dog walking is likely due to the need for short toileting walks when there is no garden or yard available. In elderly owners longer daily duration and distance of dog walking was reported for those who did not have a backyard [60]. A reduction in the size of backyards over time has also been suggested as a motivator for people to walk their dogs more often [16]; however in the one study conducted so far, there was no association between yard size and dog walk frequency [39]. Overall, it appears that the relationship between features of the physical environment and dog walking behaviour varies according to the study country of origin and thus is influenced by significant variations in urbanicity and cultural differences.

Finally, there has been little empirical research of the effect of weather or season on dog walking. The few findings from these key studies combined with other related research suggests that dog walkers at least appear to be less dependent than other walkers on variables such as the weather $[61,62]$, temperature [51], time of the year/ season [51,63] or the day of the week [64]. However, hot weather has been identified as a constraint in visiting a dog park [57].

\section{Owner-related factors: demographics}

There was mixed evidence of an association between dog walking and owners' gender, age, education, and income (Table 5). Moreover, there appears to be no evidence of an association between employment status and dog walking
$[27,34]$. There was also mixed evidence that living with other people or having dependents is associated with dog walking, limited evidence for marital status and there was no evidence that other members in the household walking the dog affects a person's dog walking activity (Table 5). In the US, owners who walk their dogs are more likely to be white than other ethnicities $[59,65]$. There is evidence that obese owners are less likely to walk their dog than healthy weight owners $[58,59,65]$, but walking the dog does not appear to be associated with general health $[58,65]$.

\section{Owner-related factors: personal beliefs}

Some studies have used health behaviour theoretical models such as the Theory of Planned Behaviour (TPB) [66] to guide their understanding of dog walking behaviour and 'intention' to walk a dog. For example, dog-walking self-efficacy is positively associated with dog walking [26] (Table 5). 'Intention' to exercise the dog predicts dog walking behaviour and there is evidence that this intention is itself influenced by various factors, including valuation of exercise, lack of time, dislike of exercise/affective attitude, instrumental attitude, subjective norm and how in control of the behaviour of dog walking owners feel (perceived behavioural control) [42,43]. However the evidence is mixed for perceived behavioural control as one study found evidence of an association with intention [43] but the other no evidence [42]. In terms of perceived barriers to dog walking, lack of time has been perceived as a significant barrier [57] with dog walks being significantly longer in duration at weekends than on weekdays [51,67]. Finally, greater levels of thought given before acquiring a dog is associated with owners reporting more frequent exercise of their dog [23].

\section{Discussion}

The investigation of dog walking is an emerging and rapidly growing area of research in the context of an obesity epidemic and the need to find cost-effective strategies for increasing population levels of physical activity. This paper provides evidence of a number of different correlates specific to dog walking behaviour, including demographic factors related to the dog and owner, physical and social environmental factors, and less easily measurable aspects of the dog-human relationship. Overall, the evidence currently suggests that dog walking may be most effectively encouraged through: 1) targeting the dog-owner relationship to increase the sense of obligation to walk the dog as well as the emotional support the dog can provide to the owner; and 2) by the provision of dog-supportive physical environments. These contexts may be the best-buy strategies for future testing of health interventions to increase dog walking amongst dog owners. They may even require implementation together thus acting at multiple levels (both 
individual and environmental) for the most effective population change [68]. However, the quality of the evidence varies, with a number of different outcomes presented and various methodological approaches that may or may not adjust for the effect of confounding factors. Only one study used a randomised controlled trial design, thus potentially providing a stronger level of evidence of a causal mechanism for targeting the perceived canine need for exercise.

A key dog-related factor to encourage dog walking appears to be the strength of the relationship with the $\mathrm{dog}$, in providing support for enjoyment for walking and a sense of obligation to walk the dog. Although there is evidence for other dog-related factors, studies suggest these disappear after adjusting for the support and motivation provided by the dog for walking $[24,25]$ or the sense of obligation to walk the dog $[26,42]$. However it would be wrong to dismiss dog-related elements as not important; it is likely that dog demographic and behavioural factors contribute to intention to walk and practicalities of walking the dog, that drive the sense of obligation and feelings of support and motivation that arise. For example, these may be stronger for larger dogs than smaller because of differences in perceived or actual exercise needs. More research is required to better understand the correlates of dog walking behaviour, in particular the perception of the amount of exercise that different dogs require. For example, dog owners report that their dog receives 'adequate' exercise yet the interpretation of this appears to vary widely as they also report exercising their dogs 0 to $>7$ times a week [23]. This may provide scope for interventions that change the perception of what a dog needs in terms of exercise and requires further investigation for which in-depth qualitative enquiry may be useful.

The evidence also suggests that interventions that strengthen the relationship between the dog and their owner may be a useful strategy; doing obedience training or simply spending time with a dog can improve the relationship with the dog and the obedience of the dog [69]. However, it is unclear whether walking with a dog leads to a stronger relationship between the owner and their dog or if an existing strong relationship leads to more walking. Likewise, behavioural issues related to the dog (e.g., aggression or fears) may result in less owner physical activity because of decreased motivation to take the dog out in a public place, but may also be caused by it, as inadequate early experiences and socialisation in dogs can lead to the development of behavioural problems [70].

The design of areas intended for dog walking and how they fulfil dog and owner needs may be an important consideration for future interventions. In order to encourage more dog owners to walk their dogs the recreational areas used for dog walking must be both pleasurable and accessible, as opposed to the common phenomenon of relegating dog access only to the few areas left after other user types have been accommodated [71]. However, it is difficult to tease out cause and effect - do regular dog walkers choose to live closer to high quality parks where they can walk their dog or does living next to a high quality park cause people to walk their dog more? In particular there must be sufficient provision for off-leash walking as this appears to be important to owners; it is perceived that quality of life of the dog would be compromised if dogs could not be walked off-leash in areas [54]. This suggests that an important function of dog walking, particularly off-leash, is enhancing dog quality of life, and thus how a public space fulfils their dogs needs is important to owners.

We also know that walking with a dog is not simply a vehicle for physical activity; it also increases the frequency of interactions with people, especially strangers [72]. However, the effect appears to be dog specific, with breed and age of dog influencing these interactions [73]. In a UK study, 92\% of owners noticed seeing the same people and their dogs regularly while walking their dog [35]. In the US, 'dog parks' are perceived as providing opportunity to meet neighbours and build community [57]. Pet ownership has also been positively associated with perceptions of neighbourhood friendliness, with pet owners score higher on social capital and civic engagement scales [74]. Dog walking is also a way to spend time with friends; in a UK study $38 \%$ of owners reported never walking their dogs with a group of friends and their dogs, but $3 \%$ did this every day [35]. If facilitation of social interactions is a potentially strong feature of dog walking practices, there may be a need to acknowledge and encourage this human need when designing interventions and space for dog walking, especially for those owners for which dog walking is a rare opportunity for social interaction (e.g., older adults). It is possible that health promotion activities focussed on increasing owner awareness of the importance to do regular physical activity may sometimes be misplaced; if the physical activity resulting from walking a dog is a secondary outcome to fulfilling other needs of the owner or dog. Owners may be more likely to participate in and sustain physical activity if they actually enjoy it, or feel that it benefits their dog, than if they are simply trying to be healthier and more active for themselves.

This review highlights a number of methodological aspects that have implications for future research and for the interpretation of our findings. The majority of studies to date have been cross-sectional in design which limits the ability to confirm the causal relationships between dog, owner, social and physical environment related factors and dog walking behaviour. Furthermore, 
the majority of studies did not use objective measures of physical activity. However there is some evidence to suggest that objective measurements of dog walking physical activity (i.e., accelerometers) correlate with selfreport measures [59].

Moreover, many studies did not adjust for the effects of confounding variables. This means that reported findings for some factors may be due to their own correlations with other factors. For example, it is important to control for dog-related demographic variables such as dog size when considering the effects of dog behaviour, and vice versa. Furthermore, the type of dog and way it behaves may also be correlated with the owner-dog relationship. This may explain the sometimes conflicting findings for some of the correlates of dog walking reviewed, for example where sometimes dog behaviour or size appears to have an effect, but not in other studies where an aspect of the relationship or support/motivation provided by the dog is also examined. Furthermore, clear evidence regarding dog-related factors (size, breed, etc.) may also be difficult to gather because they are hard to accurately measure in self-completed surveys and there may not be sufficient power to detect differences, especially in the often small sample sizes used. It is also possible that interactions between dog age and breed as well as a non-linear relationship between dog age and dog walking behaviour may exist and this should be considered in future studies. Few studies in this review sought to adjust for well-known correlates of general physical activity, such as: socio-demographic (gender, age, country of origin, education, occupation, children at home $<18$ years); perceived physical-environmental; and family social support and intrapersonal factors [24]. Even where multivariable analyses were performed, some adjusted for a wide range of non-significant factors due to their theoretical importance and high face validity (e.g. $[24,25,58])$, whereas others did not clearly report adjustment for other factors (e.g. $[23,42])$. Dog walking behaviour outcomes also varied widely between studies with some at the level of the dog and others at the level of the owner (see Table 1).

Finally, future research should include context-specific measures of both the dependent and independent variables [75]. For example, context-specific measures of intrapersonal factors such as 'intention to walk the dog' as opposed to measuring 'intention to walk' in general (e.g. [42]) may better capture the factors associated with dog walking behaviour. In addition, it is unclear whether correlates influence dog walking behaviour and/or if they effect intention to walk the dog. As highlighted in our proposed theoretical model (Figure 1) future research should examine the pathways through which the different correlates influence dog walking behaviour. A survey tool has been designed specifically for this type of research (the Dogs And Physical Activity Tool; DAPA Tool) [76]. The DAPA
Tool has been shown to be a reliable tool for measuring important attributes and scales relating to dog owners' physical activity behaviour and the context-specific factors that affect owners' walking with their dogs. Future studies would be more easily comparable if consistent data collection methods were used, however, the DAPA Tool is likely to require further development for effective use in different contexts and cultural locations than its original design (for example to study children or other cultures than Australia where it was developed).

This review highlights that there has been little explicit research as to what dog walking actually is, to both the owner and the dog; what actually happens on a 'dog walk' and what functions it performs. It is recommended that physical activity behaviours are considered separately, in order to study and implement the most effective strategies to fit this particular physical activity context [30]. Previously, dog walking has been considered a leisure-time or recreational physical activity behaviour (e.g., [16,63,77-82]); non-exercise related walking [83]; chores/errands [84]; and even commuting physical activity [85]. Thus we recommend that in future dog walking is considered in its own right. The dog walking experience also depends on whether the dog is on or off-leash. Most dogs stay fairly close to their owners [35,54] and a large proportion of the walk is spent sniffing, especially when off leash or if the dog is a 'gundog' type [86]. Further research is required to better understand the dog walking experience: its intended purpose (for recreation or transport or just a chore that has to be done); the intensity (light, moderate or vigorous) and pattern (long bouts or numerous short bouts) of the physical activity undertaken with a dog; and how this is affected by factors such as how the dog behaves; which in turn is affected by dog breed, whether the dog is on or off leash as well as the environment the dog is being walked in. Finally, while dog walking has the potential to facilitate increased physical activity in owners, forcing dogs to exercise with us may also raise ethical questions [87] for example if there is a mismatch between the needs of the dog and the wishes of the owner.

This emerging area of research is also affected by a frequent problem in sociological research; that people, including researchers, already have 'common sense' knowledge of what dog walking is to them. However, it cannot be assumed that this is the same across society; there is unlikely to be a single 'type' of dog walker and there are likely to be cultural differences even between western countries for example, the use of official 'dog parks' (in the USA but not the UK) where owners passively sit or stand is common [57]. Further research in different countries and cultures is required to target the benefits to be gained from dog walking, as multiple strategies are likely to be required; for example, initiation of dog walking, maintenance, or increasing frequency may all 
benefit from different strategies. Further qualitative and observational research is required to enhance understanding of the phenomenon and its complexity, in particular surrounding the 'intensity' of physical activity that occurs during 'a dog walk' and the everyday barriers that affect dog owners regardless of their best intentions to walk more. Much of the research to date has focused on why people do walk their dog rather than why they do not, and there has been very little research into how policy affects dog-walking behaviour.

The purpose of this review was to provide information on correlates that may be useful for the design of interventions to encourage dog walking. However, intervention studies need to measure dog walking in the context of overall physical activity, in order to determine whether the intervention increases the physical activity of those who are already physically active, or changes the environment in which physical activity occurs. Although encouraging those owners who already walk their dogs regularly to walk even more is not problematic, the priority for improving population health should be to increase the physical activity of those owners who currently do not undertake physical activity on a regular basis. Intervention studies must also openly report the tool used to deliver the intervention, designed with our model of specific behavioural correlates in mind so that these can be clearly identified and their effects measured. For example it is difficult to evaluate exactly how giving 'persuasive material about canine health from walking' [41] is acting on owner's dog walking behaviour: which particular aspects of canine health is it describing benefits to? (physical? mental?); is it changing perceived exercise requirements?; is it increasing the owner's overall perception of the valuation of exercise for dog?; is it increasing the sense of dog obligation?; or even using the subjective norm of significant others depending on how the intervention is delivered (e.g.; veterinarians)?

Finally, this review has prioritised the individual health impacts that may be gained by encouraging a person to walk more with their dog. However, the positive impacts of dog owners walking their dogs may also extend to non-owners, through an increased sense of safety in the neighbourhood (see [88]) as well as sense of community and social capital [74]. It must also be acknowledged that a few studies have reported negative impacts of dog walking or dogs as a barrier to physical activity, for example through concerns about loose/stray dogs and dog waste [88-90] or being an injury hazard through bites or falls [91-94]. There are also concerns over the impact of dog walking on wildlife [53,95-100]. Any attempts to promote dog walking activity must be done in a manner that is also mindful to the potential negative impacts of dog walking on society; and any attempts to prevent or reduce dog walking and its associated impacts should also be aware of the negative effect this may have on the health of dogs and their owners.

\section{Conclusion}

Current evidence suggests that dog walking may be most effectively encouraged through targeting the dog-owner relationship and by providing dog-supportive physical environments. More research is required to investigate the influence of individual owner and dog factors on 'intention' to walk the dog as well as the influence of human social interaction whilst walking a dog. The effects of policy and cultural practices relating to dog ownership and walking should also be investigated. Future studies must account for the effects of confounding between variables, and preferably use longitudinal designs or where possible test the effectiveness of identified correlates using interventions with a controlled design, in order to infer causality.

\section{Competing interests}

All authors own a dog(s). The authors declare that they have no other conflicts of interest.

\section{Authors' contributions}

CW designed the study, collected and analysed the data and drafted the manuscript. HC and RC contributed to study design, analysis and interpretation and drafting of the manuscript. All authors read and approved the final manuscript.

\section{Acknowledgements}

This work was supported by a Medical Research Council Population Health Scientist Fellowship [grant number G1002402] held by Carri Westgarth. Hayley Christian is supported by an Australian National Health and Medical Research Council (NHMRC)/National Heart Foundation Early Career Fellowship [grant number 1036350]. Funding bodies had no role in design, collection, analysis, and interpretation of data; in the writing of the manuscript; or in the decision to submit the manuscript for publication.

\section{Author details}

'Department of Epidemiology and Population Health, Institute of Infection and Global Health, and School of Veterinary Science, Faculty of Health and Life Sciences, University of Liverpool, Leahurst Campus, Chester High Road, Neston, Cheshire CH64 7TE, UK. ${ }^{2} \mathrm{NIHR}$ Health Protection Research Unit in Emerging and Zoonotic Infections, Liverpool L69 7BE, UK. ${ }^{3}$ Centre for the Built Environment and Health, School of Population Health, and Telethon Kids Institute, The University of Western Australia (M707), 35 Stirling Highway, Crawley, WA 6009, Australia.

Received: 21 August 2013 Accepted: 28 April 2014

Published: 20 August 2014

\section{References}

1. Herzog H: The impact of pets on human health and psychological wellbeing: fact, fiction, or hypothesis? Curr Dir Psychol Sci 2011, 20:236-239.

2. McNicholas J, Gilbey A, Rennie A, Ahmedzai S, Dono J-A, Ormerod E: Pet ownership and human health: a brief review of evidence and issues. BMJ 2005, 331:1252-1254.

3. Christian H, Westgarth C, Bauman A, Richards EA, Rhodes R, Evenson K, Mayer JA, Thorpe RJ: Dog ownership and physical activity: A review of the evidence. J Phys Act Health 2013, 10:750-759.

4. Pet Population Statistics. [http://www.pfma.org.uk/pet-population/

5. Pet Ownership Statistics. [http://www.acac.org.au/pet_care.html]

6. US pet-ownership estimates from the APPA for 2012. [http://www.humanesociety. org/issues/pet_overpopulation/facts/pet_ownership_statistics.html]

7. Facts about Physical Activity. [http://www.cdc.gov/physicalactivity/data/ facts.html] 
8. Physical Activity in Australia: A Snapshot, 2007-08. [http://www.abs.gov.au/ ausstats/abs@.nsf/Lookup/4835.0.55.001main+features32007-08]

9. Health Survey for England - 2008: Physical activity and fitness. [http://www. hscic.gov.uk/pubs/hse08physicalactivity]

10. Bull FC, and the Expert Working Groups: Physical Activity Guidelines in the UK: Review and Recommendations. Loughborough University: School of Sport, Exercise and Health Sciences; 2010.

11. Owen CG, Nightingale CM, Rudnicka AR, Ekelund U, McMinn AM, van Sluijs EMF, Griffin SJ, Cook DG, Whincup PH: Family dog ownership and levels of physical activity in childhood: findings from the child heart and health study in England. Am J Public Health 2010, 100:1669-1671.

12. Salmon J, Timperio A, Chu B, Veitch J: Dog ownership, dog walking, and children's and parents' physical activity. Res Q Exerc Sport 2010, 81:264-271.

13. Christian H, Trapp G, Lauritsen C, Wright K, Giles-Corti B: Understanding the relationship between dog ownership and children's physical activity and sedentary behaviour. Pediatr Obes 2013, 8:392-403.

14. Mathers M, Canterford L, Olds T, Waters E, Wake M: Pet ownership and adolescent health: Cross-sectional population study. J Paediatr Child Health 2010, 46:729-735.

15. Sirard JR, Patnode CD, Hearst MO, Laska MN: Dog ownership and adolescent physical activity. Am J Prev Med 2011, 40:334-337.

16. Cutt HE, Giles-Corti B, Wood LJ, Knuiman MW, Burke V: Barriers and motivators for owners walking their dog: results from qualitative research. Health Promot J Austr 2008, 19:118-124.

17. Motooka M, Koike H, Yokoyama T, Kennedy NL: Effect of dog-walking on autonomic nervous activity in senior citizens. Med J Aust 2006, 184:60-63.

18. Peel E, Douglas M, Parry O, Lawton J: Type 2 diabetes and dog walking: patients' longitudinal perspectives about implementing and sustaining physical activity. Br J Gen Pract 2010, 60:570-577.

19. Chan CB, Spierenburg M, Ihle SL, Tudor-Locke C: Use of pedometers to measure physical activity in dogs. J Am Vet Med Assoc 2005, 226:2010-2015.

20. Robertson ID: The association of exercise, diet and other factors with owner-perceived obesity in privately owned dogs from metropolitan Perth, WA. Prev Vet Med 2003, 58:75-83.

21. Bland IM, Guthrie-Jones A, Taylor RD, Hill J: Dog obesity: owner attitudes and behaviour. Prev Vet Med 2009, 92:333-340.

22. Warren BS, Wakshlag JJ, Maley M, Farrell TJ, Struble AM, Panasevich MR, Wells MT: Use of pedometers to measure the relationship of dog walking to body condition score in obese and non-obese dogs. Br J Nutr 2011, 106:S85-589.

23. Rohlf VI, Bennett PC, Toukhsati S, Coleman G: Beliefs underlying dog owners' health care behaviors: results from a large, self-selected, internet sample. Anthrozoös 2012, 25:171-185.

24. Cutt H, Giles-Corti B, Knuiman M: Encouraging physical activity through dog walking: Why don't some owners walk with their dog? Prev Med 2008, 46:120-126.

25. Christian H, Giles-Corti B, Knuiman M: "I'm Just a'-Walking the Dog" correlates of regular dog walking. Fam Community Health 2010, 33:44-52.

26. Hoerster KD, Mayer JA, Sallis JF, Pizzi N, Talley S, Pichon LC, Butler DA: Dog walking: Its association with physical activity guideline adherence and its correlates. Prev Med 2011, 52:33-38.

27. Oka K, Shibata A: Prevalence and correlates of dog walking among Japanese dog owners. J Phys Act Health 2012, 9:786-793.

28. Bauman AE, Russell SJ, Furber SE, Dobson AJ: The epidemiology of dog walking: an unmet need for human and canine health. Med J Aust 2001, 175:632-634.

29. Tudor-Locke C, van der Ploeg HP, Bowles HR, Bittman M, Fisher K, Merom D, Gershuny J, Bauman A, Egerton M: Walking behaviours from the 1965-2003 American heritage time use study (AHTUS). Int J Behav Nutr Phys Act 2007, 4:45

30. Giles-Corti B, Timperio A, Bull F, Pikora T: Understanding physical activity environmental correlates: increased specificity for ecological models. Exerc Sport Sci Rev 2005, 33:175-181.

31. Stokols D: Establishing and Maintinging Healthy Environments - Toward a social ecology of health promotion. Am Psychol 1992, 47:6-22.

32. GRADE: Grading quality of evidence and strength of recommendations. BMJ 2004, 328:1490.

33. OCEBM Levels of Evidence Working Group: The Oxford 2011 Levels of Evidence. Oxford Centre for Evidence-Based Medicine. [http://www.cebm.net/ wp-content/uploads/2014/06/CEBM-Levels-of-Evidence-2.1.pdf]

34. Westgarth C, Gaskell RM, Pinchbeck GL, Bradshaw JWS, Dawson S, Christley RM: Walking the dog: exploration of the contact networks between dogs in a community. Epidemiol Infect 2009, 137:1169-1178.
35. Westgarth C, Pinchbeck GL, Bradshaw JWS, Dawson S, Gaskell RM, Christley RM: Dog-human and dog-dog interactions of 260 dog-owning households in a community in Cheshire. Vet Rec 2008, 162:436-442.

36. Heuberger R, Wakshlag J: Characteristics of ageing pets and their owners: dogs v. cats. Br J Nutr 2011, 106:S150-S153.

37. Tami $G$, Barone A, Diverio $S$ : Relationship between management factors and dog behavior in a sample of Argentine Dogos in Italy. J Vet Cardiol Beha-Clin App Res 2008, 3:59-73.

38. Podberscek AL, Serpell JA: Environmental influences on the expression of aggressive behaviour in English Cocker Spaniels. Appl Anim Behav Sci 1997, 52:215-227.

39. Kobelt AJ, Hemsworth PH, Barnett JL, Coleman GJ: A survey of dog ownership in suburban Australia-conditions and behaviour problems. Appl Anim Behav Sci 2003, 82:137-148.

40. Degeling C, Burton L, McCormack GR: An investigation of the association between socio-demographic factors, dog-exercise requirements, and the amount of walking dogs receive. Can J Vet Res 2012, 76:235-240.

41. Rhodes RE, Murray H, Temple VA, Tuokko H, Higgins JW: Pilot study of a dog walking randomized intervention: Effects of a focus on canine exercise. Prev Med 2012, 54:309-312.

42. Brown SG, Rhodes RE: Relationships among dog ownership and leisure-time walking in western Canadian adults. Am J Prev Med 2006, 30:131-136.

43. Rohlf VI, Toukhsati S, Coleman GJ, Bennett PC: Dog Obesity: Can Dog Caregivers' (Owners') feeding and exercise intentions and behaviors be predicted from attitudes? J Appl Anim Welf Sci 2010, 13:213-236.

44. Johnson RA, Meadows RL: Dog-Walking: motivation for adherence to a walking program. Clin Nurs Res 2010, 19:387-402.

45. Rogers J, Hart LA, Boltz RP: The role of pet dogs in casual conversations of elderly adults. J Soc Psychol 1993, 133:265-277.

46. Kushner RF, Blatner DJ, Jewell DE, Rudloff K: The PPET study: people and pets exercising together. Obesity 2006, 14:1762-1770.

47. Knight S, Edwards V: In the company of wolves - The physical, social, and psychological benefits of dog ownership. J Aging Health 2008, 20:437-455.

48. Suminski RR, Poston WSC, Petosa RL, Stevens E, Katzenmoyer LM: Features of the neighborhood environment and walking by US adults. Am J Prev Med 2005, 28:149-155.

49. Carver A, Salmon J, Campbell K, Baur L, Garnett S, Crawford D: How do perceptions of local neighborhood relate to adolescents' walking and cycling? Am J Health Promot 2005, 20:139-147.

50. Arnberger A, Haider W: Social effects on crowding preferences of urban forest visitors. Urban For Urban Gree 2005, 3:125-136.

51. Arnberger A, Hinterberger B: Visitor monitoring methods for managing public use pressures in the Danube Floodplains National Park, Austria. J Nat Conserv 2003, 11:260-267.

52. Arnberger A, Eder R: Exploring coping behaviours of Sunday and workday visitors due to dense use conditions in an urban forest. Urban For Urban Gree 2012, 11:439-449.

53. Williams KJH, Weston MA, Henry S, Maguire GS: Birds and beaches, dogs and leashes: Dog owners' sense of obligation to leash dogs on beaches in Victoria, Australia. Hum Dimens Wildl 2009, 14:89-101.

54. Bekoff $M$, Meaney CA: Interactions among dogs, people, and the environment in Boulder, Colorado: A case study. Anthrozoös 1997, 10:23-31.

55. Underhill-Day JC, Liley D: Visitor patterns on southern heaths: A review of visitor access patterns to heathlands in the UK and the relevance to Annex I bird species. Ibis 2007, 149:112-119.

56. Ioja Cl, Rozylowicz L, Patroescu M, Nita MR, Vanau GO: Dog walkers' vs. other park visitors' perceptions: The importance of planning sustainable urban parks in Bucharest, Romania. Landsc Urban Plan 2011, 103:74-82.

57. Lee H-S, Shepley M, Huang C-S: Evaluation of off-leash dog parks in Texas and Florida: A study of use patterns, user satisfaction, and perception. Landsc Urban Plan 2009, 92:314-324.

58. McCormack GR, Rock M, Sandalack B, Uribe FA: Access to off-leash parks, street pattern and dog walking among adults. Public Health 2011, 125:540-546.

59. Coleman KJ, Rosenberg DE, Conway TL, Sallis JF, Saelens BE, Frank LD, Cain K: Physical activity, weight status, and neighborhood characteristics of dog walkers. Prev Med 2008, 47:309-312.

60. Scheibeck R, Pallauf M, Stellwag C, Seeberger B: Elderly people in many respects benefit from interaction with dogs. Eur J Med Res 2011, 16:557-563.

61. Temple V, Rhodes R, Higgins JW: Unleashing physical activity: an observational study of park use, dog walking, and physical activity. J Phys Act Health 2011, 8:766-774. 
62. Gobster PH: Recreation and leisure research from an active living perspective: Taking a second look at urban trail use data. Leis Sci 2005, 27:367-383

63. Lail P, McCormack GR, Rock M: Does dog-ownership influence seasonal patterns of neighbourhood-based walking among adults? A longitudinal study. BMC Public Health 2011, 11:148.

64. Ploner A, Brandenburg C: Modelling visitor attendance levels subject to day of the week and weather: A comparison between linear regression models and regression trees. J Nat Conserv 2003, 11:297-308.

65. Thorpe RJ Jr, Simonsick EM, Brach JS, Ayonayon H, Satterfield S, Harris TB, Garcia M, Kritchevsky SB: Hlth Aging Body Composition S: dog ownership, walking behavior, and maintained mobility in late life. J Am Geriatr Soc 2006, 54:1419-1424

66. Ajzen I: The theory of planned behaviour. Organ Behav Hu Perf 1991, 50:179-211.

67. Sallander M, Hagberg M, Hedhammar A, Rundgren M, Lindberg JE: Energy-intake and activity risk factors for owner-perceived obesity in a defined population of Swedish dogs. Prev Vet Med 2010, 96:132-141.

68. Sallis JF, Cervero RB, Ascher W, Henderson KA, Kraft MK, Kerr J: An ecological approach to creating active living communities. Annu Rev Public Health 2006, 27:297-322.

69. Clark Gl, Boyer WN: The effects of dog obedience training and behavioural counselling upon the human-canine relationship. Appl Anim Behav Sci 1993, 37:147-159.

70. Pierantoni L, Albertini M, Pirrone F: Prevalence of owner-reported behaviours in dogs separated from the litter at two different ages. Vet Rec 2011, 169:468

71. Jackson H, Blackshaw JK, Marriott J: Public Open Space and Dogs. A Design and Management Guide for Open Space Professionals and Local Government Petcare Information and Advisory Service: Melbourne, Australia; 1995.

72. McNicholas J, Collis GM: Dogs as catalysts for social interactions: Robustness of the effect. Br J Psychol 2000, 91:61-70.

73. Wells DL: The facilitation of social interactions by domestic dogs. Anthrozoös 2004, 17:340-352

74. Wood L, Giles-Corti B, Bulsara M: The pet connection: pets as a conduit for social capital? Soc Sci Med 2005, 61:1159-1173.

75. Giles-Corti B, Donovan RJ: Relative influences of individual, socia environmental, and physical environmental correlates of walking. Am J Public Health 2003, 93:1583-1589.

76. Cutt HE, Giles-Corti B, Knuiman MW, Pikora TJ: Physical activity behavior of dog owners: development and reliability of the Dogs and Physical Activity (DAPA) Tool. J Phys Act Health 2008, 5:S73-S89.

77. Ball K, Timperio A, Salmon J, Giles-Corti B, Roberts R, Crawfords D: Personal, social and environmental determinants of educational inequalities in walking: a multilevel study. J Epidemiol Community Health 2007, 61:108-114

78. Yabroff KR, Troiano RP, Berrigan D: Walking the Dog: Is pet ownership associated with physical activity in California? J Phys Act Health 2008 5:216-228.

79. Cleland V, Ball K, Hume C, Timperio A, King AC, Crawford D: Individual, social and environmental correlates of physical activity among women living in socioeconomically disadvantaged neighbourhoods. Soc Sci Med 2010, 70:2011-2018.

80. Gillum RF, Obisesan TO: Living with companion animals, physical activity and mortality in a US National Cohort. Int J Environ Res Public Health 2010, 7:2452-2459.

81. Reeves MJ, Rafferty AP, Miller CE, Lyon-Callo SK: The impact of dog walking on leisure-time physical activity: results from a population-based survey of Michigan adults. J Phys Act Health 2011, 8:436-444.

82. Sjogren K, Hansson EE, Stjernberg L: Parenthood and factors that influence outdoor recreational physical activity from a gender perspective. BMC Public Health 2011, 11:93.

83. Thorpe RJ Jr, Kreisle RA, Glickman LT, Simonsick EM, Newman AB, Kritchevsky S: Physical activity and pet ownership in year 3 of the health ABC Study. J Aging Phys Act 2006, 14:154-168.

84. Tudor-Locke C, Ham SA: Walking behaviors reported in the American Time Use Survey 2003-2005. J Phys Act Health 2008, 5:633-647.

85. Corseuil MW, Schneider IJC, Santos Silva DA, Costa FF, Silva KS, Borges L, d'Orsi E: Perception of environmental obstacles to commuting physical activity in Brazilian elderly. Prev Med 2011, 53:289-292.

86. Westgarth C, Christley RM, Pinchbeck GL, Gaskell RM, Dawson S, Bradshaw JWS: Dog behaviour on walks and the effect of use of the leash. Appl Anim Behav Sci 2010, 125:38-46.
87. Spencer S, Decuypere E, Aerts S, De Tavernier J: History and ethics of keeping pets: comparison with farm animals. J Agri Environ Ethics 2006 19:17-25.

88. Toohey AM, Rock MJ: Unleashing their potential: a critical realist scoping review of the influence of dogs on physical activity for dog-owners and non-owners. Int J Behav Nutr Phys Act 2011, 8:46.

89. Wilson DK, Kirtland KA, Ainsworth BE, Addy CL: Socioeconomic status and perceptions of access and safety for physical activity. Ann Behav Med 2004, 28:20-28.

90. de Vries SI, Bakker I, van Mechelen W, Hopman-Rock M: Determinants of activity-friendly neighborhoods for children: results from the SPACE study. Am J Health Promot 2007, 21:312-316.

91. Stevens JA, Teh SL, Haileyesus T: Dogs and cats as environmental fall hazards. J Saf Res 2010, 41:69-73.

92. Willmott H, Greenheld N, Goddard R: Beware of the dog? An observational study of dog-related musculoskeletal injury in the UK. Accid Anal Prev 2012, 46:52-54.

93. Pluijm SMF, Smit JH, Tromp EAM, Stel VS, Deeg DJH, Bouter LM, Lips P: A risk profile for identifying community-dwelling elderly with a high risk of recurrent falling: Results of a 3-year prospective study. Osteoporos Int 2006, 17:417-425.

94. Lindström R, Tegenborg S, Bylund PO, Björnstig U, Eriksson A: Survey of personal injuries caused by dogs and cats in Umeå. Walking the dog was the activity most often related to injury. Lakartidningen 2002, 99:656-662.

95. Banks PB, Bryant JV: Four-legged friend or foe? Dog walking displaces native birds from natural areas. Biol Lett 2007, 3:611-613.

96. Sterl P, Brandenburg C, Arnberger A: Visitors' awareness and assessment of recreational disturbance of wildlife in the Donau-Auen National Park J Nat Conserv 2008, 16:135-145.

97. Harby A: Dogs and nature reserves: can they co-exist? Ecos 2010, 31:68-71.

98. Steven R, Pickering C, Guy Castley J: A review of the impacts of nature based recreation on birds. J Environ Manag 2011, 92:2287-2294.

99. Burger J, Jeitner C, Clark K, Niles LJ: The effect of human activities on migrant shorebirds: Successful adaptive management. Environ Conserv 2004, 31:283-288.

100. Langston RHW, Liley D, Murison G, Woodfield E, Clarke RT: What effects do walkers and dogs have on the distribution and productivity of breeding European Nightjar Caprimulgus europaeus? Ibis 2007, 149:27-36.

101. Ham SA, Epping J: Dog walking and physical activity in the United States. Prev Chronic Dis 2006, 3:A47.

102. Schofield G, Mummery K, Steele R: Dog ownership and human healthrelated physical activity: an epidemiological study. Health Promot J Austr 2005, 16:15-19.

103. Masters AM, McGreevy PD: Dogkeeping practices as reported by readers of an Australian dog enthusiast magazine. Aust Vet J 2008, 86:18-25.

\section{doi:10.1186/1479-5868-11-83}

Cite this article as: Westgarth et al:: How might we increase physical activity through dog walking?: A comprehensive review of dog walking correlates. International Journal of Behavioral Nutrition and Physical Activity 2014 11:83

\section{Submit your next manuscript to BioMed Central and take full advantage of:}

- Convenient online submission

- Thorough peer review

- No space constraints or color figure charges

- Immediate publication on acceptance

- Inclusion in PubMed, CAS, Scopus and Google Scholar

- Research which is freely available for redistribution 